\title{
Brief
}

\section{Should large mediastinal hematomas be drained after endovascular repair of ruptured descending thoracic aorta?}

Said Yassin, MD, John Marek, MD, Jess Schwartz, MD, Jorge Wernly, MD, Charles Dietl, MD, Stuart Pett, MD, and Mark Langsfeld, MD, Albuquerque, NM

From the Department of Surgery, University of New Mexico, Albuquerque, NM. Received for publication April 6, 2007; accepted for publication April 20, 2007.

Address for reprints: Said Yassin, MD, Department of Surgery, University of New Mexico, MSC 10-5610, 1 University of New Mexico. Albuquerque, NM 87131 (Email: syassin@salud.unm.edu).

J Thorac Cardiovasc Surg 2007;134:1040-1 $0022-5223 / \$ 32.00$

Copyright $(\odot) 2007$ by The American Association for Thoracic Surgery

doi:10.1016/j.jtcvs.2007.04.037

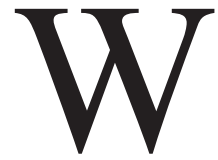

e report a case of a mediastinal hematoma caused by a ruptured Stanford type $\mathrm{B}$ aortic dissection, which resulted in delayed necrosis of the membranous wall of the left main bronchus 28 days after the successful endovascular repair of the thoracic aorta. This complication has not been reported.

\section{Clinical Summary}

A 52-year-old woman with a history of hypertension and alcoholism had a 24-hour history of severe back pain, dyspnea, and vomiting. She had a computed tomographic scan that demonstrated acute type B dissection and a mediastinal hematoma of $7 \times 4.5 \mathrm{~cm}$ compressing the trachea, carina, bilateral main stem bronchi, and distal left lobar bronchi (Figure 1, A), with bilateral pleural effusions.

She underwent easy intubation with a single-lumen endotracheal tube, followed by endovascular stenting of the descending thoracic aorta with two polytetrafluoroethylene endoprostheses (Gore-Tex prostheses; W. L. Gore \& Associates, Inc, Flagstaff, Airz) sizes $28 \times 10$ and $26 \times 10$. A completion aortogram and a repeat computed tomographic scan on the third postoperative day confirmed the obliteration of the false lumen above the renal arteries and ruled out any endoleak or extravasation (Figure 1,B).

The postoperative course was uneventful. A tube inserted into the left side of the chest drained a moderate amount of dark blood. She was extubated without consequences; how-

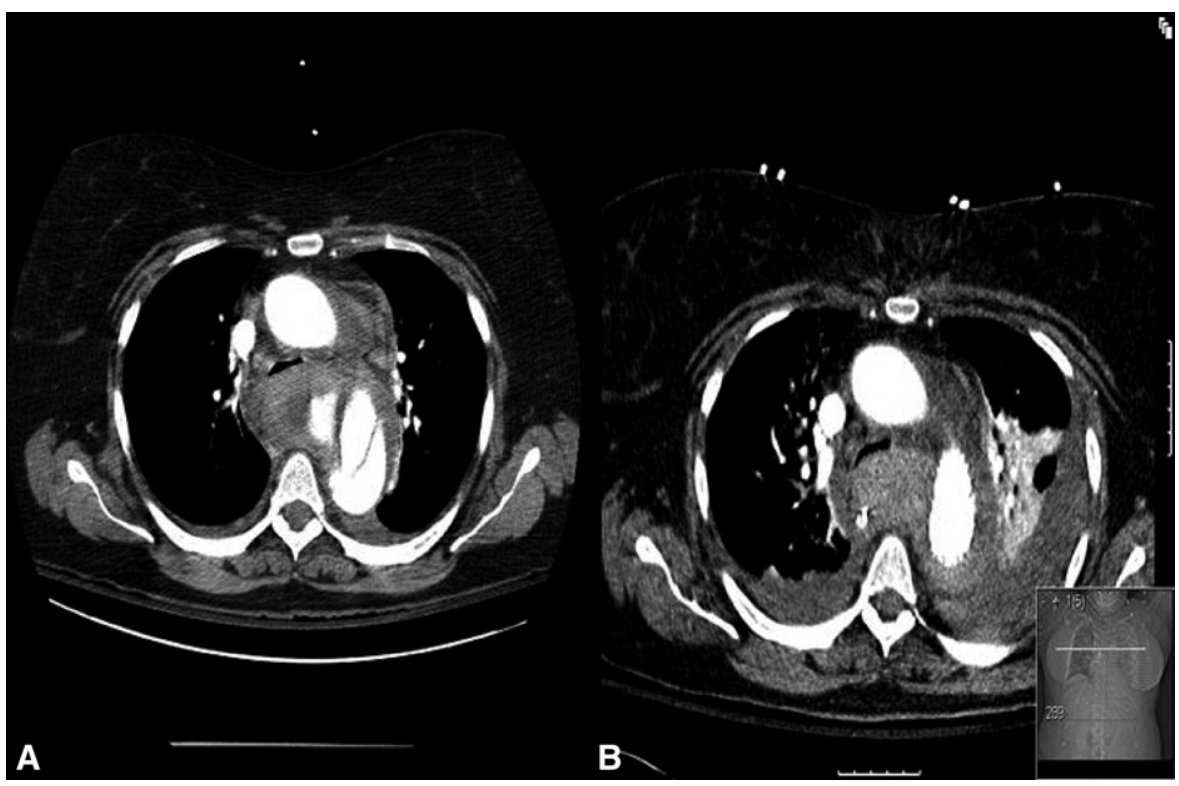

Figure 1. A, Preoperative computed tomographic scan demonstrating the aortic dissection with contrast extravasation and the mediastinal hematoma compressing the airway. B, Postoperative computed tomographic scan demonstrating the successful endovascular repair with the airways remaining compressed. 


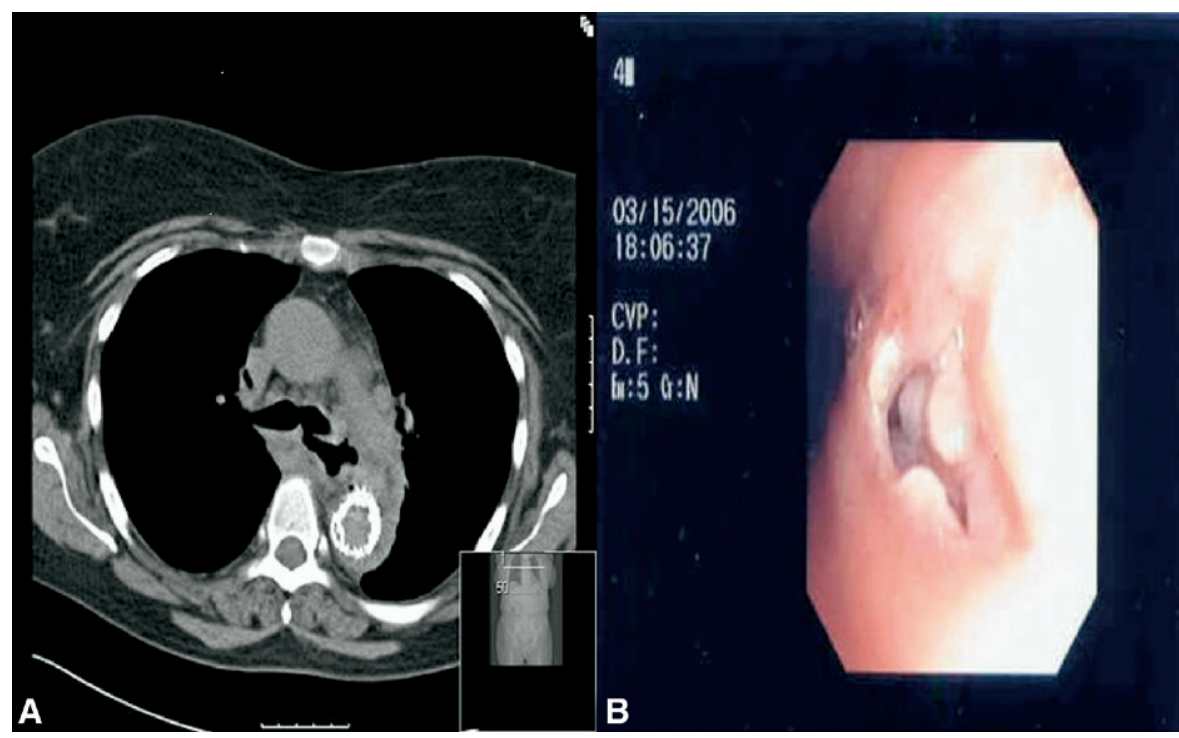

Figure 2. A, Computed tomographic scan after 28 days demonstrating decrease in the size of the hematoma with an air pocket connecting to the left main stem bronchus at the carina. B, Bronchoscopic scan showing a defect in the membranous wall of the left main bronchus.

ever, her hospital stay was prolonged as a result of alcohol withdrawal. She was discharged home on postoperative day 13 .

Two weeks after her discharge, she came to the emergency department with nausea, dysphagia, and hemoptysis. She had normal vital signs and no abnormalities on the chest x-ray film. A computed tomographic scan showed decreased size of the mediastinal hematoma and a fistula of the left main stem bronchus (Figure 2, A). Bronchoscopic examination showed a 1.5 $\times 1 \mathrm{~cm}$ defect in the membranous wall of the proximal left main bronchus (Figure 2, B). The defect was closed with a split-thickness skin graft and intercostal muscle flap. Unfortunately, the patch dehisced after 2 days and required multiple revisions that resulted in sepsis, multiple system organ failure, and subsequently the patient's death.

\section{Discussion}

Dissection of the descending thoracic aorta (Stanford type B) presents a great clinical challenge because the preferred treatment is still not well defined. In general, early surgical intervention is reserved for cases complicated by early expansion, rupture or pending rupture, or failure of medical management. Surgery is associated with a $20 \%$ to $30 \%$ risk of hospital mortality and $9 \%$ to $15 \%$ risk of neurologic complication. ${ }^{1}$

Medical therapy, the treatment of choice in the overwhelming majority of patients, has also been recognized to result in a far from attractive long-term prognosis. It is associated with $10 \%$ hospital mortality and $70 \%$ persistent patency of the false lumen. In $20 \%$ to $30 \%$ of cases the false lumen becomes aneurysmal. ${ }^{2}$

Endovascular repair provides a minimally invasive, relatively safe alternative that will minimize the risk of rupture as well as late aneurysmal complications because the false lumen is eliminated in $80 \%$ of cases. $^{3}$ The success rate is $98 \%$ in the selected cohort, in-hospital mortality $5.2 \%$, risk of neurologic complication $5 \%$, and overall survival at 2 years $88.8 \%$. $^{3,4}$

Complication rate is significantly higher in patients with acute dissection than that in patients with chronic dissection, aneurysmal disease, or aortic rupture resulting from blunt chest trauma or penetrating aortic ulcers. Furthermore, in patients with acute dissection, the presence of mediastinal hematoma was found to be one of the most important preprocedural denominators of death. ${ }^{5}$

Despite its availability in Europe and South America, no endograft is approved for this purpose in the United States. Therefore, for most patients, medical management remains the treatment of choice, pending results of prospective randomized clinical trials comparing all available therapeutic options.

In this case, we believe that the injury was a result of the pressure from the hematoma on the wall of the left main bronchus, which eventually caused tissue necrosis. Exclusion of the left bronchial arteries that usually arise directly from the aorta just below the level of the tracheal bifurcation by the stent graft might have contributed to this unusual complication. Retrospectively, a question can be raised as to whether drainage of the hematoma in addition to the repair of the aorta could have prevented this complication.

\section{References}

1. Elefteriades A, Lovoulos J, Coady A, Tellides G, Kopf GS, Rizzo JA. Management of descending aortic dissection. Ann Thorac Surg. 1999; 67:2002-5.

2. Mehta RH, Bossone E, Evangelista A, O'Gara PT, Smith DE, Cooper $\mathrm{JV}$, et al, on behalf of the International Registry of Acute Aortic Dissection Investigators. Acute type B aortic dissection in elderly patient: clinical features, outcomes and simple risk stratification rule. Ann Thorac Surg. 2004;77:1622-9.

3. Eggebrecht H, Nienaber CA, Neuhauser M, Baumgart D, Kische S, Schmermund A, et al. Endovascular stent graft placement in aortic dissection: a meta-analysis. Eur Heart J. 2006;27:489-98.

4. Brandt M, Hussel K, Walluscheck KP, Muller-Hulsbeck S, Jahnke T, Rahimi A, et al. Stent graft repair versus open surgery for the descending aorta: a case control study. J Endovasc Ther. 2004;11: 535-8.

5. Eggebrecht H, Schmermund A, Herold U, Baumgart D, Martini S, Kuhnt O, et al. Endovascular stent graft placement for acute and contained rupture of the descending thoracic aorta. Catheter Cardiovasc Interv. 2005;66:474-82. 